\title{
MEDIUM-TERM PATENCY AND ANATOMIC CHANGES AFTER DIRECT BRONCHIAL ARTERY REVASCULARIZATION IN LUNG AND HEART-LUNG TRANSPLANTATION WITH THE INTERNAL THORACIC ARTERY CONDUIT
}

Martin A. Nørgaard, MD ${ }^{a}$

Fritz Efsen, MD ${ }^{\mathrm{b}}$

Claus B. Andersen, $\mathrm{MD}^{\mathrm{c}}$

Ulrik G. Svendsen, $\mathrm{MD}, \mathrm{PhD}^{\mathrm{d}}$

Gösta Pettersson, $\mathrm{MD}, \mathrm{PhD}^{\mathrm{a}}$

\begin{abstract}
Objective: Our purpose was to study the 2-year patency of direct bronchial artery revascularization in lung transplantation. We wanted to clarify whether the revascularized bronchial artery system is functional after 2 years, whether bronchial artery vascularity changes with time, and whether posttransplantation bronchial artery disease is arteriographically evident after 2 years. Methods: Bronchial artery revascularization is performed by anastomosing the internal thoracic artery to as many bronchial artery orifices in the donor descending aorta as possible. Twenty-three patients surviving 2 years or more have had internal thoracic artery-bronchial arteriography performed 1 month and 2 years after transplantation. One-month and 2-year arteriograms have been compared. Results: Two-year patency of the internal thoracic artery conduit was $100 \%$. The appearance of the bronchial arteries was unchanged after 2 years in 11 patients. A unilateral or bilateral increase in vascularity was found in two and seven patients, respectively. In three patients new vessels, not visible on the first arteriogram, had appeared. In four patients one or more small vessels visible on the first arteriogram had disappeared on the second arteriogram. We have found no arteriographic signs of bronchial artery disease, such as stenosis of the bronchial arteries, and no arteriographic evidence of arteriosclerotic disease in the internal thoracic artery. Conclusion: The internal thoracic artery is an excellent conduit for bronchial artery revascularization, with a 2-year patency of $100 \%$ in 23 patients. Only minor changes in the bronchial arteriograms have been found. ( $\mathrm{J}$ Thorac Cardiovasc Surg 1997;114:326-31)
\end{abstract}

T he lungs have a dual blood supply: the pulmonary arteries, which provide venous blood under low pressure, and the bronchial arteries, which provide oxygenated blood under arterial pressure. The bronchial arteries follow the bronchi far out into the lung parenchyma. Besides supplying the bronchi, they have been shown to contribute arterial blood supply to lung tissue, mediastinal tissue, esophagus, mediastinal and hilar lymph nodes, pericardium, medias-

From the Departments of Cardiothoracic Surgery, ${ }^{a}$ Radiology, Pathology, ${ }^{c}$ and Internal Medicine $B,{ }^{d}$ The National University Hospital (Rigshospitalet), Copenhagen, Denmark.

Received for publication Jan. 20, 1997; revisions requested March 17, 1997; revisions received April 14, 1997; accepted for publication April 28, 1997.

Address for reprints: Martin A. Nørgaard MD, Department of Cardiothoracic Surgery, RT, 2152, Rigshospitalet, Blegdamsvej 9, 2100 Copenhagen, Denmark.

Copyright (C) 1997 by Mosby-Year Book, Inc.

$0022-5223 / 97 \$ 5.00+0 \quad \mathbf{1 2 / 1 / 8 2 9 2 1}$ tinal pleura, vagal and sympathetic nerves, and even, to a minor extent, to the myocardium. ${ }^{1}$ Lung transplantation has stimulated an interest in the role and importance of the bronchial arteries.

The logical method to prevent bronchial and lung ischemia after lung and heart-lung transplantation (HLTX) is direct bronchial artery revascularization (BAR). The bronchial artery circulation has been shown to be beneficial in lung transplantation in laboratory animals, in addition to the improved healing of the airway anastomosis. Reduced ischemia-reperfusion injury by improved lung edema clearance has been demonstrated. ${ }^{2,3}$ Improved ability of the lungs to resist and fight infection seems probable. ${ }^{4,5}$ Mucociliary clearance has been shown to be decreased after bronchial devascularization and denervation in autotransplanted canine lungs. ${ }^{4}$ Finally, it has been proposed that ischemia could be a factor in the pathogenesis of obliterative bronchiolitis, ${ }^{6}$ and hopes have been expressed 
that BAR might reduce the prevalence of this condition. ${ }^{7-9}$

Inasmuch as early results have improved with lung transplantation without BAR since the frequency of airway problems has been reduced, most lung transplant teams have come to believe that transplanted lungs do well without BAR. ${ }^{10}$ Although short-term results may be considered acceptable or even good, long-term results after lung transplantation remain unsatisfactory. ${ }^{11}$ According to our view, ischemia resulting from neglect of the bronchial arteries has not been excluded as a probable cause of problems and poor outcome after lung transplantation and HLTX.

BAR was introduced clinically in 1992 in Bordeaux ${ }^{12,13}$ and in London, ${ }^{7}$ with the main purpose being to improve airway healing. Both centers performed en bloc double lung transplantation (DLTX). A saphenous vein graft was used as the conduit in Bordeaux and a left internal thoracic artery (ITA) was used as the conduit in London. These two series, as well as our own, have shown that BAR is possible with good early results. ${ }^{8,14,15}$

In Copenhagen en bloc DLTX with BAR using the left ITA has been performed since 1992 as the preferred method of lung transplantation. In 63 cases (double lung [DLTX], single lung [SLTX], and heart-lung transplantation) with BAR we demonstrated an arteriographically monitored early success rate of $94 \%{ }^{15}$ The ITA was selected as the conduit because its patency was expected to be superior to that of the saphenous vein graft. If the beneficial effect of BAR in lung transplantation goes beyond primary healing of the airway anastomosis, long-term patency should be important. On the basis of a Kaplan-Meier survival proportion of $83 \%$ after 1 and 2 years in our patients having DLTX ${ }^{16}$ as compared with 1- and 2-year survivals of $66 \%$ and $57 \%$ in the total group of patients having bilateral or DLTX in the International Society for Heart and Lung Transplantation (ISHLT) statistics, ${ }^{11}$ we have found it relevant to study the medium-term patency of the revascularized bronchial artery system and changes in the bronchial artery circulation with time after transplantation. Our aims were to clarify whether the revascularized bronchial arteries are still open after 2 years, whether bronchial artery vascularity changes with time, and whether a posttransplantation bronchial artery disease similar to posttransplantation coronary artery disease is arteriographically evident after 2 years. Furthermore, we have tested for significant correlations between improved bronchial vascularity versus bronchiolitis obliterans syndrome, number of antibiotic treatments given, number of rejection episodes found at transbronchial biopsies, or number of rejection treatments given.

\section{Patients and methods}

In Copenhagen direct BAR with the left ITA used as the conduit has been performed in 58 en bloc DLTXs, 13 SLTXs, and 10 HLTXs from January 1992 to October 1996.

The revascularization is performed by anastomosing the distal end of the ITA to as many bronchial artery orifices in the descending aorta as possible. The aim is revascularization of all identified bronchial arteries, but revascularization of one large artery is considered acceptable.

All patients are routinely scheduled for cine ITAbronchial arteriography, early (approximately 1 month) and 2 years after the transplantation. Patients in whom BAR had failed at the early examination were not reexamined.

So far, 23 of 27 consecutive 2-year survivors have been reexamined, 20 of 22 having DLTX, one of two having SLTX, and two of three having HLTX. The two patients having DLTX, one with complete BAR and one with incomplete bilateral BAR 1 month after transplantation, have refused to have the 2-year arteriographic examination performed. One patient having SLTX and one having HLTX have refused ever to have arteriography performed. No other surviving patient has been lost to follow-up.

The cine ITA-bronchial arteriogram is performed by means of the Seldinger technique. The tip of a $6 \mathrm{~F}$ Cordis IM catheter (Cordis Corp., Miami, Fla., catalog No. 532 623 ) is introduced into the origin of the ITA under fluoroscopic control. By means of hand injection of 6 to 8 $\mathrm{ml}$ of contrast medium (Ultravist $370 \mathrm{mg}$ iodine per milliliter), arteriograms are obtained in the anteroposterior, 45-degree left anterior oblique, and 45-degree right anterior oblique projections.

The surgical records and all cine films have been carefully studied, and schematic drawings of the vascular anatomy have been made in each case. The early and 2-year arteriograms were compared with the use of two cinearteriography projectors (Tagarno $35 \mathrm{CX}$ ) simultaneously. Changes in the classification of BAR success, as well as disappearance, appearance, increase, and decrease in size of bronchial arteries between the first and the second arteriographic studies, have been recorded. In addition, the presence of bronchial artery disease, such as stenosis of the bronchial arteries or the ITA, has been carefully looked for.

Classification of the arteriographic findings. ${ }^{15}$ The following classification has been used for evaluation of the arteriograms: This classification applies to SLTX, DLTX, and HLTX with BAR.

Complete BAR: Clear visualization of bronchial arteries on the transplanted side(s) (DLTX, HLTX, SLTX); each lobe is supplied by at least one lobar ramus. 
Table I. Arteriographic classification at arteriography approximately 1 month (1 to 5 months) and 2 years after transplantation

\begin{tabular}{|c|c|c|c|c|c|c|}
\hline \multirow{2}{*}{$\begin{array}{c}\text { Patient } \\
\text { No. }\end{array}$} & \multicolumn{2}{|c|}{ Classification } & \multirow[b]{2}{*}{ Notes } & \multirow[b]{2}{*}{ BOS } & \multirow{2}{*}{$\begin{array}{l}\text { No. of } \\
\text { infection } \\
\text { episodes* }\end{array}$} & \multirow{2}{*}{$\begin{array}{l}\text { No. of } \\
\text { rejection } \\
\text { episodest }\end{array}$} \\
\hline & First arteriogram & Second arteriogram & & & & \\
\hline \multicolumn{7}{|l|}{ DLTX } \\
\hline 1 & $\begin{array}{l}\text { Incomplete bilateral } \\
\text { BAR }\end{array}$ & $\begin{array}{l}\text { Incomplete bilateral } \\
\text { BAR }\end{array}$ & $\begin{array}{l}\text { Bilateral hypertrophy, especially on the } \\
\text { left side }\end{array}$ & No & 1 & $1(2)$ \\
\hline 2 & Complete BAR & Complete BAR & Light bilateral hypertrophy & Yes & 6 & $1(0)$ \\
\hline 3 & $\begin{array}{l}\text { Incomplete hemilateral } \\
\text { BAR }\end{array}$ & $\begin{array}{l}\text { Incomplete hemilateral } \\
\text { BAR }\end{array}$ & $\begin{array}{l}\text { A few small irregular vessels on the } \\
\text { left side have disappeared. One } \\
\text { small subcarinal vessel has appeared. }\end{array}$ & Yes & 11 & $2(6)$ \\
\hline 4 & Complete BAR & Complete BAR & Minor hypertrophy on the left side & No & 0 & $1(1)$ \\
\hline 5 & Complete BAR & Complete BAR & Unchanged & No & 0 & $1(0)$ \\
\hline 6 & Complete BAR & Complete BAR & Unchanged & No & 2 & $3(3)$ \\
\hline 7 & Complete BAR & Complete BAR & Unchanged & Yes & 3 & $2(2)$ \\
\hline 8 & $\begin{array}{l}\text { Incomplete bilateral } \\
\text { BAR }\end{array}$ & Complete BAR & $\begin{array}{l}\text { Bilateral hypertrophy. Pouch at the } \\
\text { anastomosis disappeared. }\end{array}$ & No & 0 & $2(1)$ \\
\hline 9 & $\begin{array}{l}\text { Incomplete bilateral } \\
\text { BAR }\end{array}$ & Complete BAR & Bilateral hypertrophy & Yes & 2 & $1(0)$ \\
\hline 10 & $\begin{array}{l}\text { Incomplete hemilateral } \\
\text { (+right) BAR }\end{array}$ & $\begin{array}{l}\text { Incomplete Hemilat- } \\
\text { eral BAR }\end{array}$ & $\begin{array}{l}\text { Small subcarinal vessels have disap- } \\
\text { peared. Basically unchanged. }\end{array}$ & Yes & 1 & $3(1)$ \\
\hline 11 & Complete BAR & Complete BAR & Unchanged & No & 3 & $1(0)$ \\
\hline 12 & $\begin{array}{l}\text { Incomplete bilateral } \\
\text { BAR }\end{array}$ & $\begin{array}{l}\text { Incomplete bilateral } \\
\text { BAR }\end{array}$ & $\begin{array}{l}\text { Bilateral hypertrophy. One new vessel } \\
\text { has appeared on the left side (previ- } \\
\text { ously supplied only by collaterals } \\
\text { from the right side). }\end{array}$ & No & 2 & $1(0)$ \\
\hline 13 & Complete BAR & Complete BAR & Unchanged & Yes & 2 & $1(1)$ \\
\hline 14 & $\begin{array}{l}\text { Incomplete bilateral } \\
\text { BAR }\end{array}$ & Complete BAR & Bilateral hypertrophy & No & 4 & $2(2)$ \\
\hline 15 & $\begin{array}{l}\text { Incomplete bilateral } \\
\text { BAR }\end{array}$ & Complete BAR & $\begin{array}{l}\text { Bilateral hypertrophy. One new vessel } \\
\text { has appeared on the left side. }\end{array}$ & No & 2 & $2(1)$ \\
\hline 16 & Complete BAR & Complete BAR & $\begin{array}{l}\text { One small vessel for the right superior } \\
\text { lobe has disappeared }\end{array}$ & No & 0 & $1(1)$ \\
\hline 17 & Complete BAR & Complete BAR & Unchanged & No & 1 & $2(2)$ \\
\hline 18 & Incomplete poor BAR & Incomplete poor BAR & $\begin{array}{l}\text { One vessel prolonged } 3 \text { to } 4 \text { times. } \\
\text { One very small vessel disappeared. }\end{array}$ & No & 1 & $1(0)$ \\
\hline 19 & Complete BAR & Complete BAR & Unchanged & No & 0 & $2(2)$ \\
\hline 20 & Complete BAR & Complete BAR & Unchanged & No & 0 & $0(0)$ \\
\hline \multicolumn{7}{|l|}{ HLTX } \\
\hline 1 & $\begin{array}{l}\text { Incomplete bilateral } \\
\text { BAR }\end{array}$ & $\begin{array}{l}\text { Incomplete bilateral } \\
\text { BAR }\end{array}$ & Unchanged & No & 1 & $2(1)$ \\
\hline 2 & $\begin{array}{l}\text { Incomplete hemilateral } \\
\text { (left) BAR }\end{array}$ & $\begin{array}{l}\text { Incomplete hemilateral } \\
\text { BAR }\end{array}$ & Unchanged & No & 1 & $2(1)$ \\
\hline \multicolumn{7}{|l|}{ SLTX } \\
\hline 1 & Complete BAR & Complete BAR & Unchanged & Yes & 1 & $1(2)$ \\
\hline
\end{tabular}

$B O S$, Bronchiolitis obliterans syndrome, defined as a decrease in forced expiratory volume in 1 second of $20 \%$ or more from the maximum volume measured after the operation.

${ }^{*}$ Number of infection episodes as defined by number of antibiotic treatments given.

$\dagger$ Number of rejection episodes found at transbronchial biopsies. Number in parentheses indicates the number of rejection treatments given.

Incomplete bilateral BAR: Visualization of bronchial arteries on two transplanted sides but sparse on one and clear on the other side (DLTX, HLTX).

Incomplete hemilateral BAR: Clear visualization of bronchial arteries on only one of two transplanted sides (DLTX, HLTX).

Incomplete poor BAR: Sparse visualization of bronchial arteries on one or two transplanted side(s) (SLTX, DLTX, HLTX).

Failed BAR: No visualization of bronchial arteries.

Bronchiolitis obliterans syndrome has been defined as an irreversible decline of forced expiratory volume in 1 second below $80 \%$ of the postoperative baseline 

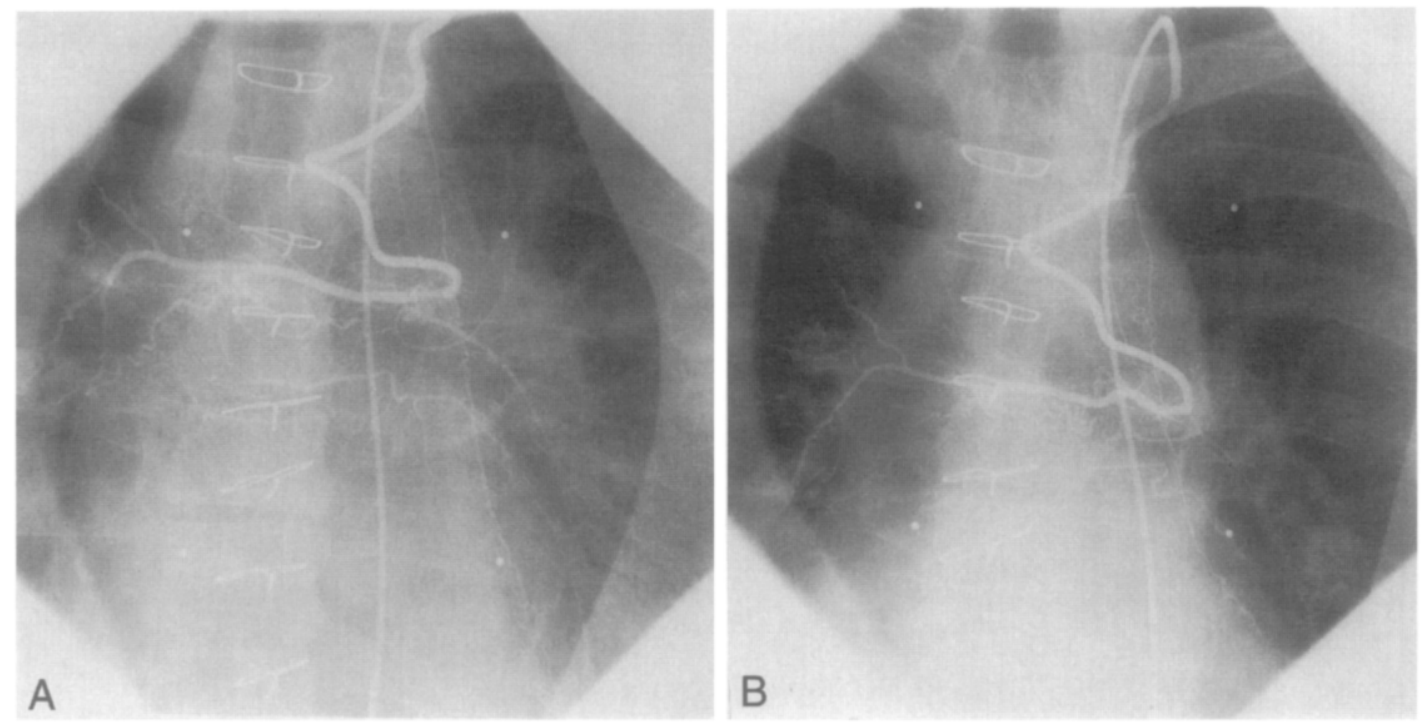

Fig. 1. A, Complete BAR 1 month after transplantation (patient 13, DLTX). B, The same patient 2 years after transplantation (complete BAR). Vascularity unchanged.

value, according to the working formulation of the ISHLT. ${ }^{17}$

\section{Results}

Twenty patients who underwent DLTX, one who had SLTX, and two who had HLTX and survived 2 years or more have had an ITA-bronchial arteriogram repeated after 2 years. The results are described in Table I. The ITA conduit and the revascularized bronchial arteries were patent in all patients reexamined after 2 years.

The appearance of the bronchial arteries was unchanged after 2 years in 11 patients (Fig. 1, $A$ and $B$ ). Unilaterally or bilaterally increased vascularity was found in two and seven patients, respectively. In three patients new vessels, not visible on the first arteriogram, had appeared (Fig. 2, $A$ and $B$ ). Four arteriograms primarily classified as showing incomplete bilateral BAR had improved to justify reclassification as complete BAR. In four patients one or more small vessels visible on the first arteriogram had disappeared on the second.

We have found no arteriographic signs of bronchial artery disease, that is, stenosis of the bronchial arteries, nor have we found any arteriographic evidence of arteriosclerotic disease in the ITA.

In patients in the DLTX group with improved vascularity (Table I, DLTX 1, 2, 3, 4, 8, 9, 12, 14, 15, and 18), the mean number of infections was 2.9 ( 0 to 11 ), whereas in those with unchanged vascularity the mean number of infectious episodes was 1.2 ( 0 to 3 ). The difference, however, was not significant (MannWhitney U test). No statistically significant correlation was noted between improved vascularity and the number of histologic rejections, rejection treatments given, or occurrences of bronchiolitis obliterans syndrome.

The total incidence of bronchiolitis obliterans syndrome 24 months after transplantation was $35 \%$ in this series of patients.

\section{Discussion}

The 2-year BAR patency was $100 \%$. The general impression is that vascularization has remained unchanged or has improved between 1 month and 2 years after transplantation. The appearance of new vessels may represent dilatation of vessels that were too small to be seen on the first arteriogram, or it may represent true neovascularization. The improved vascularization per se indicates a need for the bronchial circulation. In earlier experimental studies it has been observed that the bronchial arteries hypertrophy in the presence of infection. ${ }^{5}$ Such a vascular response to infection is normal in other tissues, and the same principle may apply to the lungs. Inasmuch as the bronchial arteries also supply the donor hilar lymph nodes, observed hypertrophy could be explained by increased activity in these nodes.

Another possible reason for improved vascularity could be development of collaterals to initially 

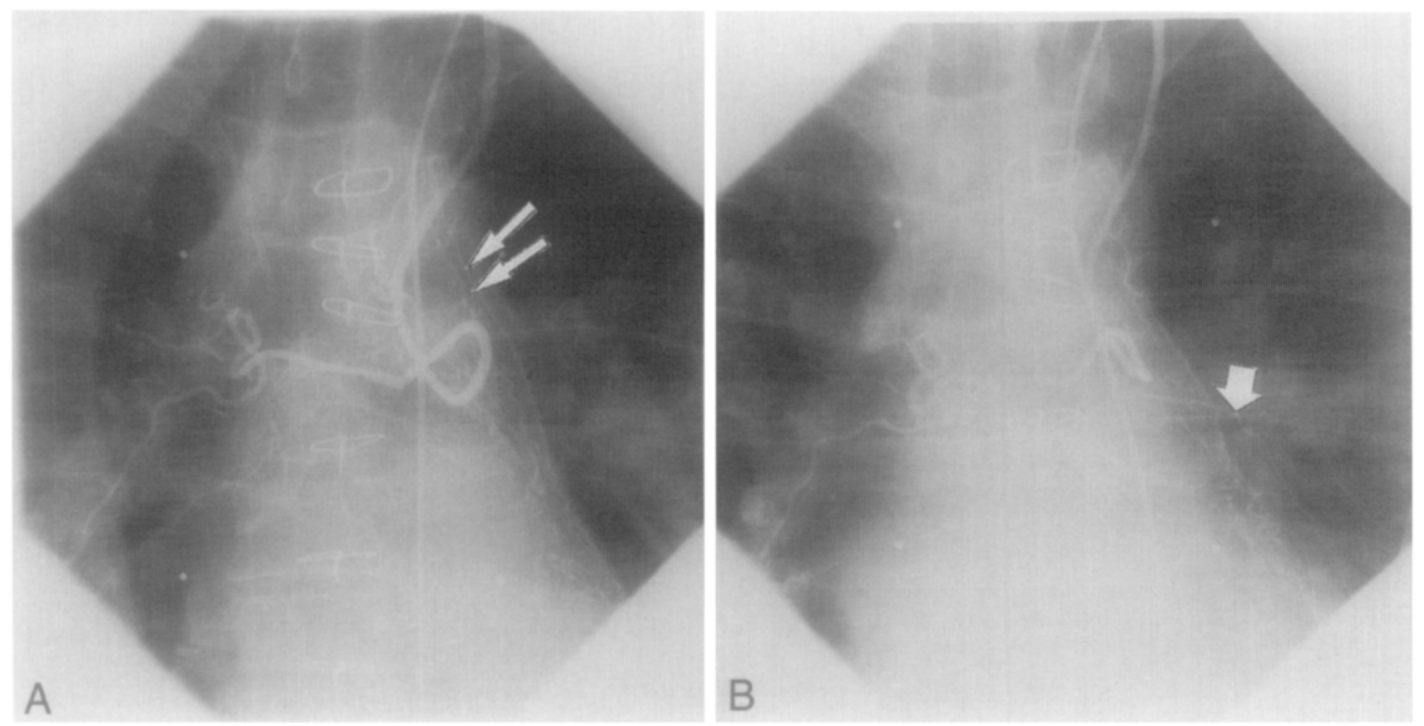

Fig. 2. A, BAR classified as incomplete bilateral BAR 1 month after transplantation (patient 12, DLTX). Thin arrows mark pericardial vessels leaving the ITA before the ITA-bronchial artery anastomosis. B, The same patient 2 years after transplantation. The arteriogram still shows incomplete bilateral BAR, but with bilateral improvement in vascularity. One new vessel has appeared on the left side (bold arrow).

poorly perfused bronchial artery branches. Additional donor bronchial neovascularization on a level not possible to visualize arteriographically may actually be more important and common than what we have found with arteriography, although one would expect spontaneous revascularization to be less effective than direct surgical revascularization.

In patients undergoing HLTX, it is quite possible that the lungs have a better arterial blood supply than estimated from the ITA-bronchial arteriogram because of coronary collaterals.

The proportions of our patients who survived DLTX at 1 year $(n=34), 2$ years $(n=22)$, and 3 years $(n=7)$ are, respectively, $83 \%, 80 \%$, and $65 \%$. When we compare these results with the ISHLT statistics, ${ }^{11}$ our survival percentages are better than those of the pooled groups of ISHLT patients receiving two transplanted lungs. In the ISHLT statistics the 1-year survivals after bilateral $(n=$ $557)$ and double lung $(n=177)$ transplantation are, respectively, $70 \%$ and $57 \%$.

The only conclusion we draw from this fact is that we should continue to do lung transplantation with BAR and wait for the long-term results. In that context it is important to know that BAR has $100 \%$ medium-term patency.

It has earlier been stated that BAR is most important during the first 15 days after transplanta- tion, allowing the airway anastomosis to heal. ${ }^{13}$ This is not necessarily true. It is our clinical impression and belief that the lungs' resistance to and management of pulmonary infections are the most important beneficial effects of BAR. The results of the present series support the view that long-term patency of BAR could be beneficial to the transplanted lung, but only a study comparing patients undergoing SLTX with and without BAR will show the effect of BAR per se. Comparison series from different centers will give imprecise information. Factors of importance after lung transplantation with BAR could be sustained mucociliary clearance, reduced mucosal bacterial adhesion, and improved lung fluid clearance, although this remains speculative.

The possible consequences of late BAR closure are still unknown. We believe collaterals will sustain viability of the bronchus, but this does not mean that BAR closure could not result in problems. To achieve more information, continuous follow-up is necessary.

In this study we have found no arteriographic evidence of posttransplantation bronchial artery disease similar to coronary artery disease seen after heart transplantation. This does not preclude the existence of this disease, and only longer follow-up will give the answer. We do not yet have sufficient autopsy material to study this histologically. 


\section{Conclusion}

The ITA is an excellent conduit for BAR, with a 2-year patency rate of $100 \%$ in 23 patients. The general impression is that bronchial vascularity has remained unchanged or has improved 2 years after transplantation. Arteriographic evidence of posttransplantation bronchial artery disease has not been found.

\section{REFERENCES}

1. Nathan $H$, Orda $R$, Barkay M. The right bronchial artery: anatomical considerations and surgical approach. Thorax 1970;25:328-33.

2. Kowalski TF, Guidotti S, Deffebach M, Kubilis P, Bishop M. Bronchial circulation in pulmonary artery occlusion and reperfusion. J Appl Physiol 1990;68:125-9.

3. Pearse DB, Wagner EM. Role of the bronchial circulation in ischemia-reperfusion lung injury. J Appl Physiol 1994;76:259-65.

4. Paul A, Marelli D, Shennib H, et al. Mucociliary function in autotransplanted, allotransplanted, and sleeve resected lungs. J Thorac Cardiovasc Surg 1989;98:523-8.

5. Charan NB, Turk GM, Dhand R. The role of bronchial circulation in lung abscess. Am Rev Respir Dis 1985;131:121-4.

6. Yousem SA, Dauber JH, Griffith BP. Bronchial cartilage alterations in lung transplantation. Chest 1990;98:1121-4.

7. Daly RC, Tadjkarimi S, Khaghani A, Banner NR, Yacoub MH. Successful double-lung transplantation with direct bronchial artery revascularization [see comments]. Ann Thorac Surg 1993;56:885-92.

8. Pettersson G, Arendrup H, Mortensen SA, et al. Early experience of double-lung transplantation with bronchial artery revascularization using mammary artery. Eur J Cardiothorac Surg 1994;8:520-4.

9. Daly RC, McGregor CG. Routine immediate direct bronchial artery revascularization for single-lung transplantation. Ann Thorac Surg 1994;57:1446-52.

10. Patterson GA. Airway revascularization: Is it necessary? [editorial; comment]. Ann Thorac Surg 1993;56:807-8.

11. Hosenpud JD, Novick RJ, Breen TJ, Daily OP. The Registry of the International Society for Heart and Lung Transplantation: eleventh official report-1994. J Heart Lung Transplant 1994;13:561-70.

12. Couraud L, Baudet E, Nashef SA, et al. Lung transplantation with bronchial revascularisation: surgical anatomy, operative technique and early results. Eur J Cardiothorac Surg 1992;6: 490-5.

13. Couraud L, Baudet E, Martigne C, et al. Bronchial revascularization in double-lung transplantation: a series of 8 patients. Bordeaux Lung and Heart-Lung Transplant Group [see comments]. Ann Thorac Surg 1992;53:88-94.

14. Arendrup H, Pettersson G, Thiis J, et al. Double-lung transplantation with bronchial artery revascularization using a mammary artery. Transplant Proc 1994;26:1809-10.

15. Nørgaard M, Efsen F, Arendrup H, Olsen P, Svendsen U, Pettersson G. Surgical and arteriographic results of bronchial artery revascularization in lung and heart-lung transplantation. J Heart Lung Transplant 1997:16:302-12

16. Pettersson G, Nørgaard M, Arendrup H, et al. Direct bronchial artery revascularization and en-bloc double lung transplantation: surgical techniques and early outcome. J Heart Lung Transplant 1997:16:320-33.

17. Cooper JD, Billingham M, Egan T, et al. A working formulation for the standardization of nomenclature and for clinical staging of chronic dysfunction in lung allografts. International Society for Heart and Lung Transplantation. J Heart Lung Transplant 1993;12:713-6. 